\title{
Adaptive Al-based two-stage control for an induction machine drive
}

\section{Vikas Kumar* and Prerna Gaur}

Div. of Instrumentation and Control Engineering,

Netaji Subhas Institute of Technology (NSIT),

Azad Hind Fauj Marg, Sector-3, Dwarka,

N. Delhi-110078, India

E-mail: sainivika@gmail.com

E-mail: prernagaur@gmail.com

*Corresponding author

\section{A.P. Mittal}

Netaji Subhas Institute of Technology (NSIT),

Azad Hind Fauj Marg, Sector-3, Dwarka,

N. Delhi-110078, India

E-mail:mittalap@gmail.com

\begin{abstract}
In this paper, a two-stage control strategy for speed control of an induction machine drive is investigated by establishing the current input model of an induction motor drive. In order to reduce the effect of machine parameter variations on the performance of the drive, AI-based adaptive neuro-fuzzy controller is implemented to act on both slip frequency and current magnitude. The effect of the load torque variations and rotor resistance variations is observed for the controller.
\end{abstract}

Keywords: neuro-fuzzy control; current input model; two-stage control; adaptive control.

Reference to this paper should be made as follows: Kumar, V., Gaur, P. and Mittal, A.P. (2013) 'Adaptive AI-based two-stage control for an induction machine drive', Int. J. Circuits and Architecture Design, Vol. 1, No. 1, pp.74-88.

Biographical notes: Vikas Kumar received his BTech in Instrumentation Engineering from Kurukshetra University and MTech Instrumentation and Control Engineering from Netaji Subhas Institute of Technology, Delhi University. Currently, he is working as a Teaching cum Research Fellow in the Division of Instrumentation and Control Engineering, NSIT. His research area includes power electronics, intelligent control techniques, sensorless control of servo drives and electric vehicle control.

Prerna Gaur received her BTech and MTech in 1988 and 1996 from G.B. Pant College of Technology, Uttaranchal, India and Delhi College of Engineering, Delhi University, India. She received her $\mathrm{PhD}$ in the field of Motion Control of PMSM. She joined the industry in 1989 and Delhi College of Engineering as a Lecturer in 1994. She is an Assistant Professor in the Instrument and Control Engineering Division at Netaji Subhas Institute of Technology, Delhi 
University since 1998. She is a life member of the Indian Society for Technical Education (ISTE) and senior member of Institute of Electrical and Electronics Engineers (IEEE). Her research interests are AI-based control techniques, electrical drives, power electronics, power quality and renewable energy resources.

\begin{abstract}
A.P. Mittal received his BE (Hons.) in Electrical Engineering from M.M.M. Engineering College, Gorakhpur (UP) in 1978, ME from University of Roorkee in 1980 and $\mathrm{PhD}$ from IIT, Delhi in 1991. He became an Assistant Professor in REC Kurukshetra and joined REC Hamirpur in 1989. He was Professor and Head in CRSCE Murthal, Haryana from 1997 to 2001. He is the HOD of Instrumentation and Control Engineering at Netaji Subhas Institute of Technology, New Delhi since 2001. He is a life member of the Indian Society for Technical Education (ISTE) and senior member of Institute of Electrical and Electronics Engineers (IEEE).
\end{abstract}

\title{
1 Introduction
}

Vector or field oriented control is the most widely adopted method for induction motor control for high performance drives as it provides excellent performance in terms of the accurate speed regulation and rapid response to the load changes. However, the vector drive is sensitive to the parameter variations (Harnefors, 2001; Ba-razzouk et al., 1997) and also the error accumulated due to definite integrals can deteriorate the drive performance. The two-stage control strategy involves an independent control of slip frequency and current magnitude, the speed, slip and current response of the drive is similar to that of field oriented control and is better compared to the scalar control. Moreover, the performance of two-stage controlled drive is less affected by the motor parameter variations (Shi et al., 2001).

The induction motor model has highly non-linear time varying dynamics so the conventional controllers in such situations become poor and unstable. Fuzzy logic controllers have been the best alternative and are widely used in a number of engineering applications for highly non-linear, uncertain and ill defined systems, however the large number of parameters needs to be determined prior to the implementation and complexity of the rule base increases as the non-linearity in the plant dynamics increases. Neural networks on the other hand can simulate any non-linear system by their powerful learning capability, adaptation and robustness (Wlas et al., 2005).

Adaptive neuro-fuzzy combine the advantages of employing expert knowledge from the fuzzy inference system and the learning capability of neural networks. Adaptive neuro-fuzzy has been successfully implemented for induction motor drive in order to compensate the effect of parameter variation for an induction machine drive (Gaur et al., 2008; Chen, 2011). This paper is focused around the implementation of adaptive neuro-fuzzy-based two-stage control for an induction machine drive. Firstly, the current input model of the induction motor is simulated, and adaptive neuro-fuzzy-based current controller is implemented, then the fuzzy slip frequency controller is designed and the same is optimised using neuro-fuzzy approach and finally the effect of machine parameter variations is observed by changing the load torque and stator resistance. 


\section{Simulink model of induction motor}

The current input of induction motor is based on the reference-frame theory of coordinate transformation is modelled as follows (Shi et al., 1997).

The current source is represented as

$$
\left\{\begin{array}{c}
i_{a s}=A \cos \left(\int \omega d t\right) \\
i_{b s}=A \cos \left(\int \omega d t-2 \pi / 3\right) \\
i_{a s}=A \cos \left(\int \omega d t+2 \pi / 3\right)
\end{array}\right.
$$

The three currents can be converted to two phase using equation (2)

$$
\left[\begin{array}{c}
i_{d s}^{e} \\
i_{q s}^{e}
\end{array}\right]=\left[\begin{array}{c}
\cos \left(\int \omega d t\right) \cos \left(\int \omega d t-120\right) \cos \left(\int \omega d t+120\right) \\
\sin \left(\int \omega d t\right) \sin \left(\int \omega d t-120\right) \sin \left(\int \omega d t+120\right)
\end{array}\right] *\left[\begin{array}{c}
i_{a s} \\
i_{b s} \\
i_{c s}
\end{array}\right]
$$

The electromagnetic torque produced by motor is given as

$$
T=\frac{p}{3 R_{r}} \frac{L_{M}}{\tau_{r}}\left(i_{q s}^{e} \lambda_{d r}^{e}-i_{d s}^{e} \lambda_{q r}^{e}\right)
$$

where

$$
\lambda_{d r}^{e}=\frac{1}{p}\left(\frac{L_{M}}{\tau_{r}} i_{d s}^{e}-\frac{1}{\tau_{r}} \lambda_{q r}^{e}+\omega_{r} \lambda_{q r}^{e}\right)
$$

and

$$
\lambda_{q r}^{e}=\frac{1}{p}\left(\frac{L_{M}}{\tau_{r}} i_{q s}^{e}-\frac{1}{\tau_{r}} \lambda_{q r}^{e}+\omega_{r} \lambda_{d r}^{e}\right)
$$

The rotor angular speed can be derived from the mechanical dynamics of the motor as follows:

$$
\begin{aligned}
& \frac{d \omega_{0}}{d t}=-\frac{c_{f}}{J_{m}+J_{L}} \omega_{0}+\frac{T-T_{L}}{J_{m}+J_{L}} \\
& \omega_{0}=\frac{1 /\left(J_{m}+J_{L}\right)}{s+c_{f} /\left(J_{m}+J_{L}\right)}\left(T-T_{L}\right)
\end{aligned}
$$

where $p$ is the no of poles $R_{r}$ is the rotor resistance per phase, $i_{d s}^{e}$ and $i_{q s}^{e}$ are the components of stator current in the excitation reference frame, $J_{m}$ and $J_{L}$ are the moment 
of inertia of the rotor and load respectively, $c_{f}$ is the coefficient of friction, $T$ is the developed mechanical torque and $\tau_{r}$ is the load torque and $T_{L}$ is the rotor time constant.

Equations (1) to (7) are used to model the induction motor in MATLAB simulation. The Simulink model of induction motor is shown in Figure 1.

Figure 1 Current input model of induction motor

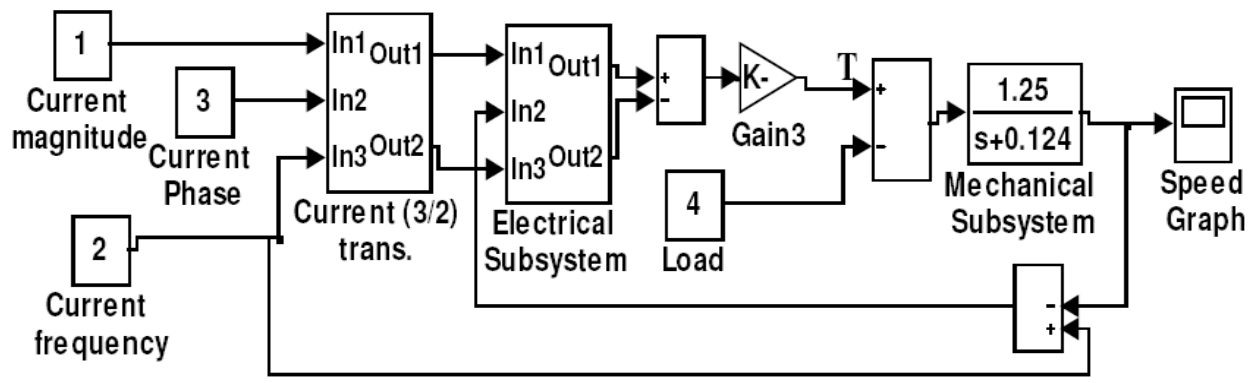

\section{Two-stage control}

In the vector control the slip frequency is kept constant during acceleration and de-acceleration period and when the torque is constant the current is also constant. These two features are used in the two-stage control of an induction machine drive. In two-stage control (Shi et al., 2001):

1 During acceleration and de-acceleration stage the stator current magnitude is kept constant, and the speed increases or decreases depending upon the input frequency so that

$$
\omega=\omega_{r}+\frac{P}{2} \omega_{0}
$$

Equation (8) is satisfied.

2 During steady state stage the input frequency $\omega$ is held constant and the speed is maintained constant by varying the stator current magnitude.

The slip frequency is given by

$$
\omega_{r}=\frac{3 R_{r} T^{*}}{P \lambda_{d r}^{e^{*} 2}}
$$

$T^{*}$ is the torque command, and $\lambda_{d r}^{e^{*}}$ is the rotor flux command. If $T^{*}$ is maintained constant during acceleration and de-acceleration, $\omega_{r}$ is also constant. As $\omega_{0}$ changes during acceleration and de-acceleration, $\omega$ has to be changed, so that equation (8) is satisfied. 
Figure 2 Two-stage control strategy of Induction motor drive

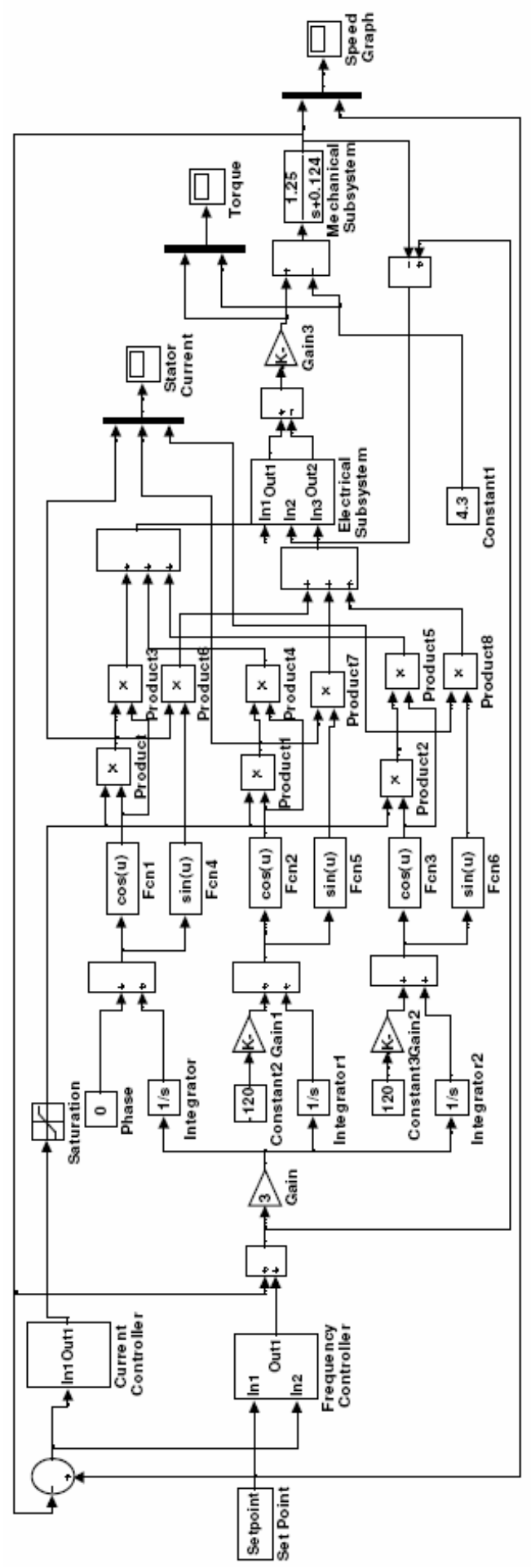


For field orientation control,

$$
\begin{aligned}
& \lambda_{q r}^{e}=0 \\
& \lambda_{d r}^{e}=\text { const. } \\
& i_{d s}^{e}=\frac{\lambda_{d r}^{e}}{L_{m}}=\text { const. as } \lambda_{d r}^{e} \text { is constant } \\
& i_{q s}^{e}=\frac{T^{*} P L_{m}}{3 L_{m} \lambda_{d r}^{e}}=\text { const. }
\end{aligned}
$$

Stator phase current $\left|I_{s}\right|$ can be expressed as:

$$
\left|I_{s}\right|=\frac{2}{3} \sqrt{i_{q s}^{e}{ }^{2}+i_{d s}^{e}}=\text { const }
$$

Based upon the above strategy and the current input model the two-stage control strategy is as shown in Figure 2.

\section{Adaptive neuro-fuzzy-based controller}

The adaptive neuro-fuzzy controller is a five layer feed forward network in which each node performs a particular function on incoming signals depending upon the function assigned to the respective node. The controller has two states, a learning state and a controlling state. In the learning state, the performance evaluation is carried out according to the feedback which represents the process state and in the controlling state the controller is required to perform the desired objective. First order Takagi-Sugeno and Kang (TSK)-based inference mechanism is used, the typical rules of a TSK first order system can be written as:

Rule1: If $x$ is $A$ and $y$ is $B$ then

$$
f=p_{1} x+q_{1} y+r_{1}
$$

Rule2: If $x$ is $A$ and $y$ is $B$ then

$$
f=p_{2} x+q_{2} y+r_{2}
$$

$p_{1}, q_{1}, r_{1}$ and $p_{2}, q_{2}, r_{2}$ are the consequent parameters. The structure of neuro-fuzzy controller is shown in Figure 3, consists of input layer, four hidden layers, and one output layer.

Layer 1 each node in this layer generated the membership grade of the input signal depending upon the node function.

Layer 2 is the rule layer of the controller or the knowledge base. The layer 2 output is calculated using product operator.

$$
w_{i}=\mu_{A i}(x)^{*} \mu_{B i}(x) \text { For } i=1,2, \ldots \ldots
$$


Layer 3 the $i^{\text {th }}$ node in layer 3 calculates the ratio of the $i^{\text {th }}$ Rule's strength to the sum of all individual rules firing strengths. The output of this layer is normalised firing strengths.

$$
W_{i}=\frac{w_{i}}{w_{1}+w_{2}}
$$

Layer 4 The node function of the output layer is.

$$
O_{i}^{4}=W_{i} f_{i}=W_{i}\left(p_{i} x+q_{i} y+r_{i}\right)
$$

These parameters are known as consequent layer parameters.

Layer 5 This node computes the summation of all incoming signals

$$
\begin{aligned}
& O_{i}^{5}=\sum_{i} W_{i} f_{i} \\
& \text { i.e., } \\
& f=W_{1} f_{1}+W_{2} f_{2} .
\end{aligned}
$$

Figure 3 Five layer ANFIS structure

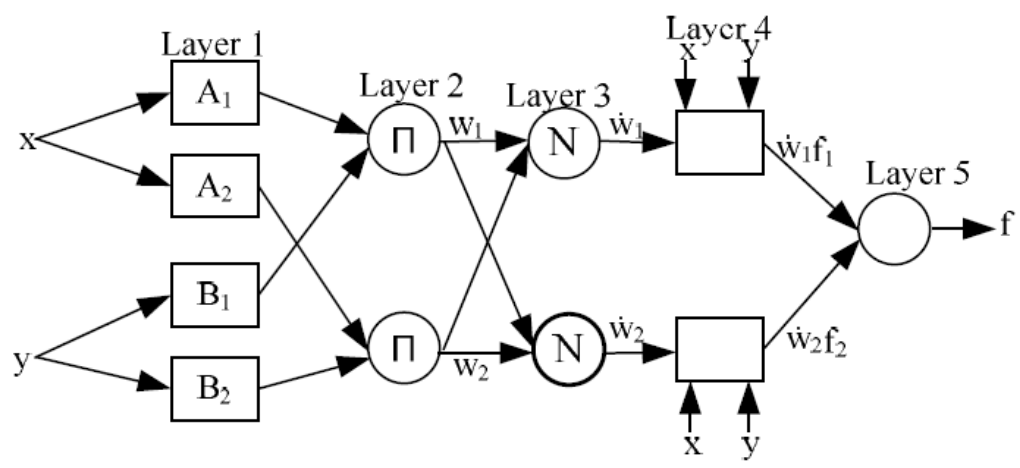

\subsection{Learning method}

Hybrid learning rule which combines the gradient descendent and least squares method for an optional parameter search is used for training. The output of the layer 4 is calculated then we used the least square estimator to find the consequent parameters, the error rate propagates backward and the premise parameters are updated using gradient descent method.

\section{Simulation implementation}

All the proposed control schemes have been implemented on $10 \mathrm{HP}$ induction motor (Appendix). The current input model as shown in Figure 2 is simulated to implement the 
adaptive neuro-fuzzy current controller. The performance of the implemented controllers is checked under load torque, rotor resistance variation.

\subsection{Fuzzy logic controller for frequency and adaptive neuro-fuzzy controller for current $(F / N F)$}

The fuzzy logic controller to control the current is designed and optimised using TSK-based neuro-fuzzy technique. The reference speed and the speed error are taken as input and the stator current magnitude is the output of the controller. Both the inputs to the neuro-fuzzy controller are normalised in the range $(-1,1)$. For this work, we have taken five membership functions in both inputs and total no of rules are 25. The shape of the membership function is generalised bell.

\subsection{Adaptive neuro-fuzzy controller for frequency and current (NF/NF)}

The fuzzy logic frequency controller is now replaced with the adaptive neuro-fuzzy scheme. The structure of the adaptive neuro-fuzzy current controller is same as in the earlier case, for adaptive neuro-fuzzy frequency control, we have used five generalised bell shape membership functions in both the inputs, and the no of rules are equal to the no. of output membership functions, i.e., 25. The performance of the controller is evaluated under parameters like load torque and rotor resistance variation. The fuzzy logic-based slip frequency and ANFIS-based current controller for induction motor is implemented using Simulink.

\subsection{Effect of load torque changes}

The load is changed from $100 \%$ to $200 \%$ of the load torque at time $\mathrm{t}=2.5 \mathrm{sec}$, again decreased to $100 \%$ at time $t=7 \mathrm{sec}$. At time $t=10 \mathrm{sec}$ load is again increased to $200 \%$ of the load torque and the effects of load torque changes are shown in Figures 9 and 10.

\subsection{Effect of rotor resistance}

The rotor resistance is increased from its initial value $R_{r}$ to $2 R_{r}$, and the performance is compared with the original speed response as shown in Figures 10 and 11.

\section{Results and discussions}

Initially, to check the performance of the controller the motor is run at the rated speed, without variation in parameters. The three phase stator currents, slip and the torque and speed response for F/NF controller are as shown in Figure 4, and for NF/NF controller in Figure 5, respectively. Initial hike in the torque response helps the drive to reach the set speed faster. The drive takes $0.95 \mathrm{sec}$ and $0.88 \mathrm{sec}$ for $\mathrm{F} / \mathrm{NF}$ and NF/NF controller respectively to reach the set speed with a steady state error of $0.98 \mathrm{rad} / \mathrm{s}$ for $\mathrm{F} / \mathrm{NF}$ controller and $0.18 \mathrm{rad} / \mathrm{s}$ for NF/NF controller. The overshoot for F/NF controller is $0.91 \%$ and for NF/NF controller is $0.72 \%$. 
Figure 4 Response of F/NF-based two-stage controller (see online version for colours)
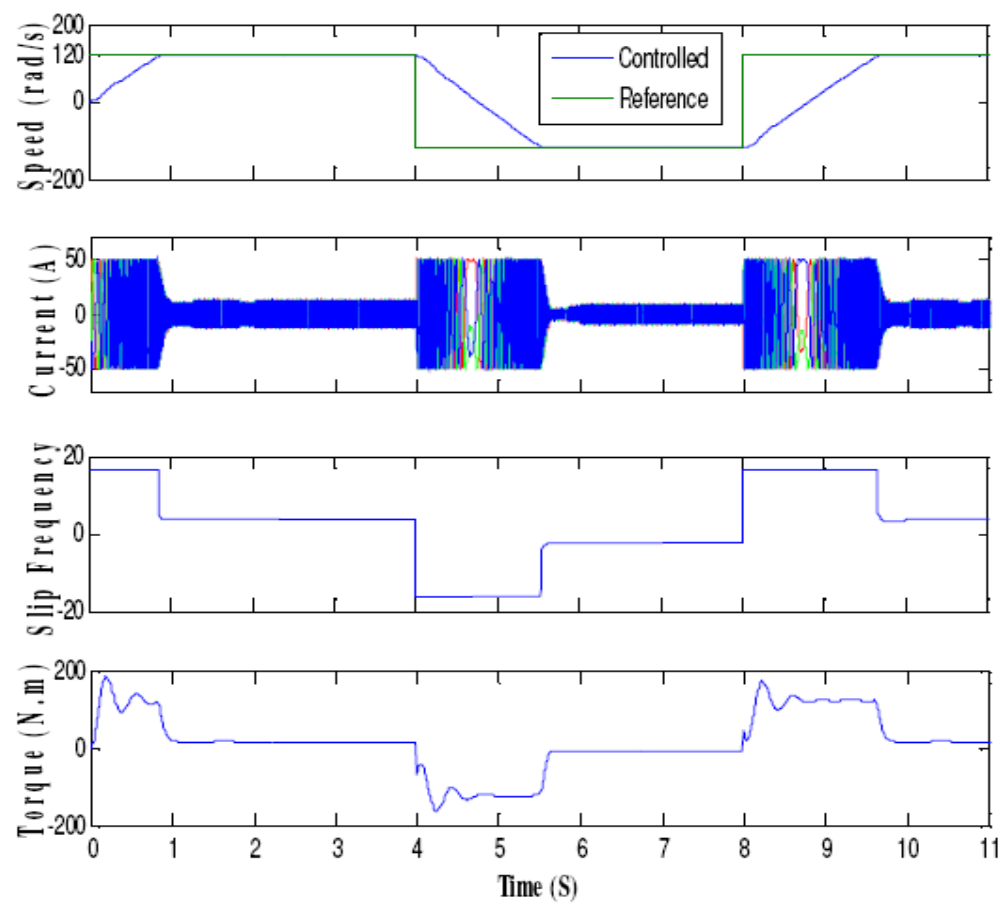

Figure 5 Response of NF/NF-based two-stage controller (see online version for colours)
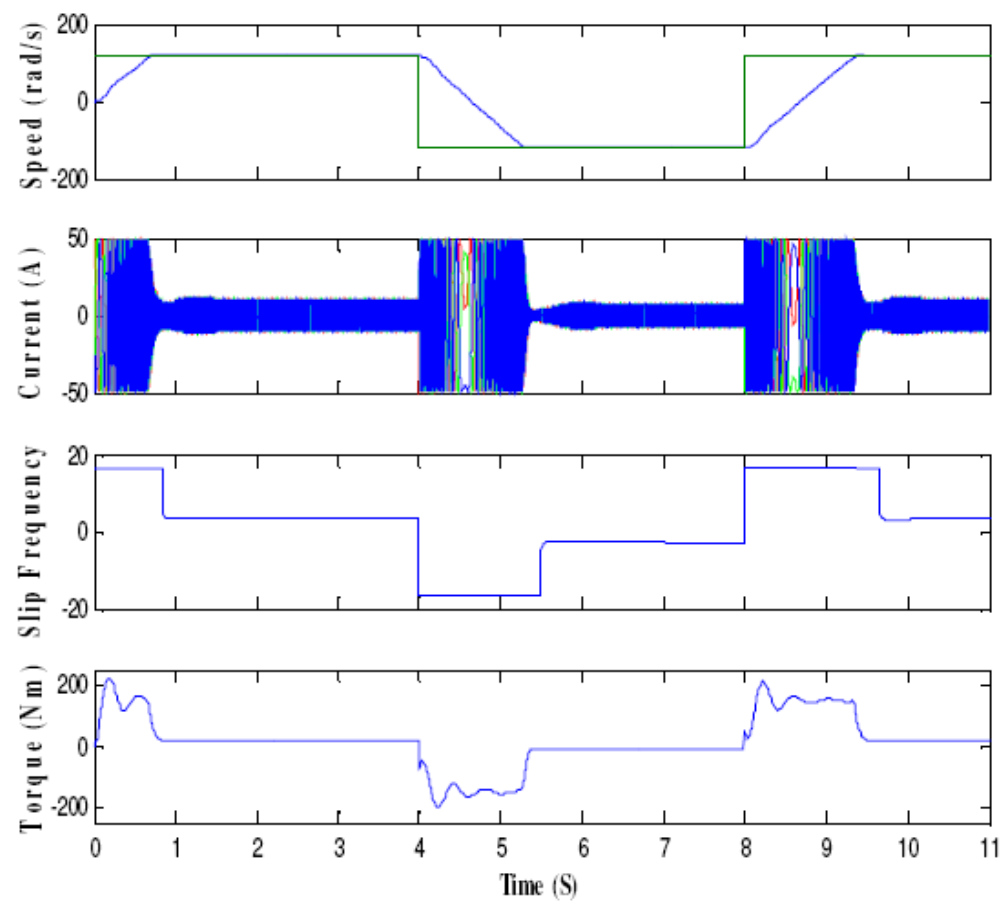
Figure 6 Speed comparison - overall performance of F/NF and NF/NF controller (see online version for colours)

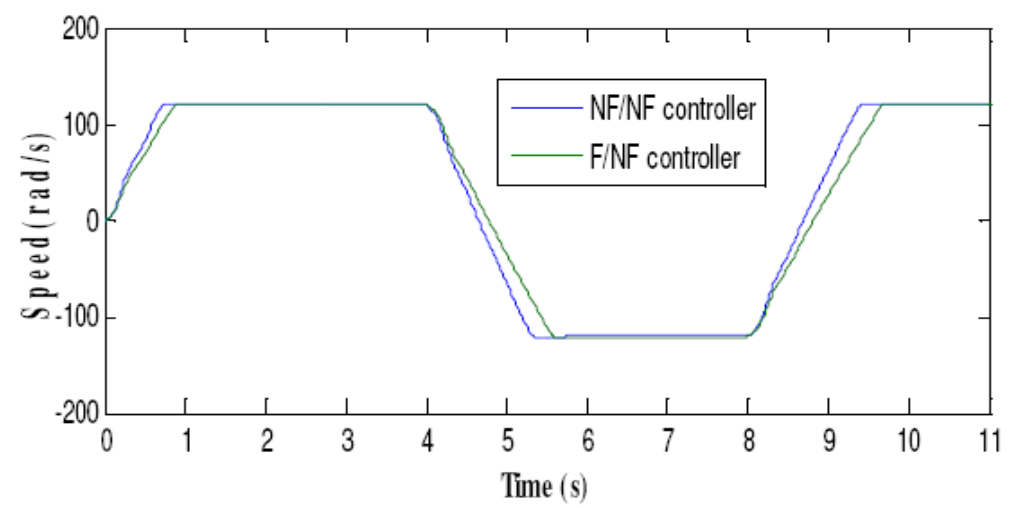

Figure 7 Speed comparison-steady state for F/NF and NF/NF controller (see online version for colours)

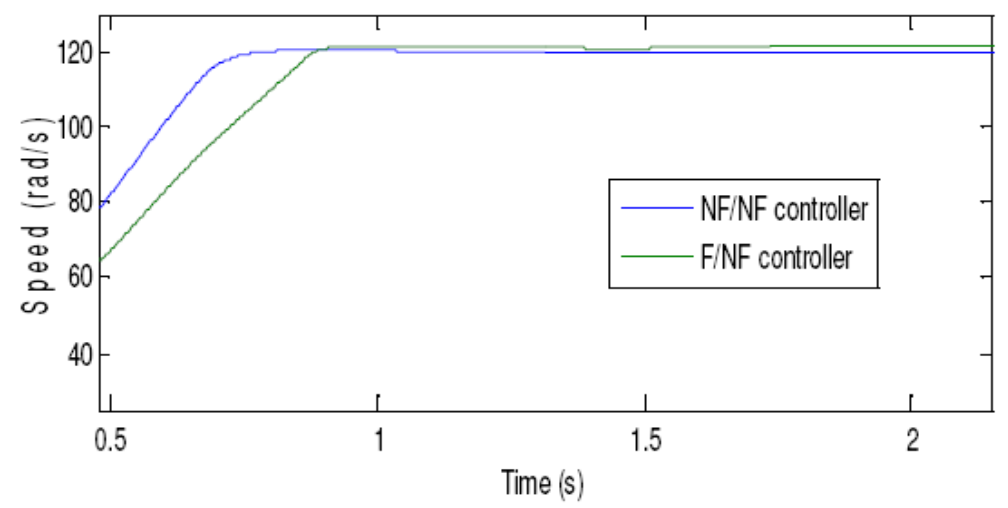

Figure 6 shows the comparison of the speed closely for both controllers. The speed response of NF/NF controller is better than the F/NF controller in terms of peak overshoot, steady state error and rise time. Figure 7 shows again the speed comparison in the steady state, the green line shows the response of the F/NF controller and the red line shows the response of the NF/NF controller, as seen the performance of NF/NF controller is better in terms of small rise time, steady state error as seen from Table 1 also.

Table 1 Performance comparison of F/NF and NF/NF controller

\begin{tabular}{lcc}
\hline Parameters & F/NF controller & NF/NF controller \\
\hline Rise time (s) & 0.95 & 0.88 \\
$\%$ over shoot & 0.91 & 0.72 \\
Steady state error & 0.98 & 0.18 \\
\hline
\end{tabular}


Figure 8 Effect of load torque variations for F/NF controller (see online version for colours)
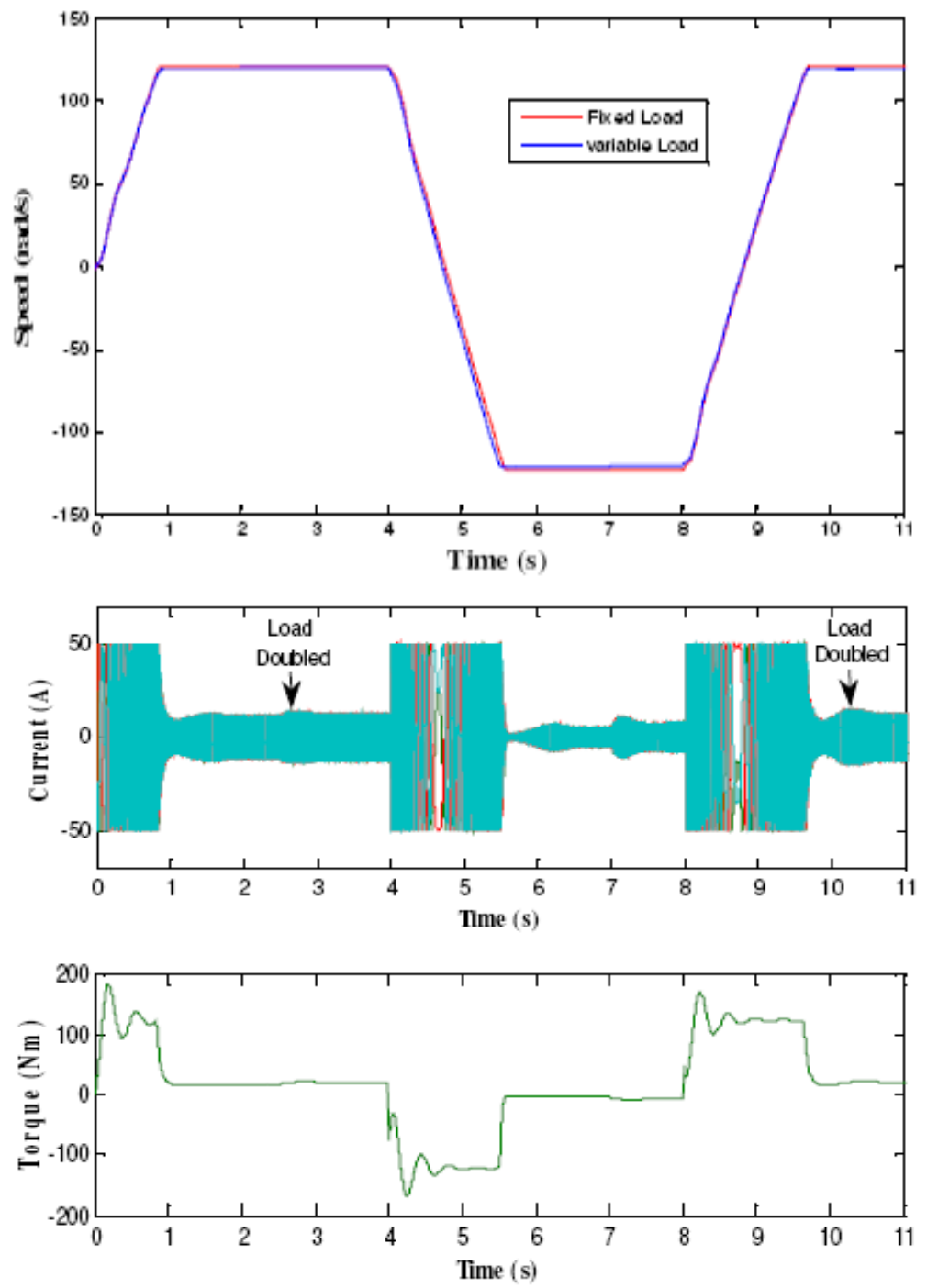

Summary of responses of performance parameters for $\mathrm{F} / \mathrm{NF}$ and NF/NF controller is shown in Table 1. The performance parameters comparison of the performance of the $\mathrm{NF} / \mathrm{NF}$ controller is better in terms of fast rise time, small overshoot and finally the small steady state error. Figure 8 shows the effect of load torque changes for F/NF controller, at $\mathrm{t}=2.5 \mathrm{sec}$ the load torque in increased from $100 \%$ to $200 \%$ again decreased to $100 \%$ at time $\mathrm{t}=7 \mathrm{sec}$. At time $\mathrm{t}=10 \mathrm{sec}$. load is again increased to $200 \%$, the speed dropped from $120.9 \mathrm{rad} / \mathrm{s}$ to $120.2 \mathrm{rad} / \mathrm{s}$ at $\mathrm{t}=2.5 \mathrm{~s}$ and is recovered to $120.7 \mathrm{rad} / \mathrm{s}$ in $0.5 \mathrm{~seconds}$. Figure 9 shows the effect of rotor resistance change for $\mathrm{F} / \mathrm{NF}$ controller, the speed error of $0.85 \mathrm{rad} / \mathrm{sec}$ is observed due to change in value of rotor resistance. 
Figure 9 Effect of load torque variations for NF/NF controller (see online version for colours)
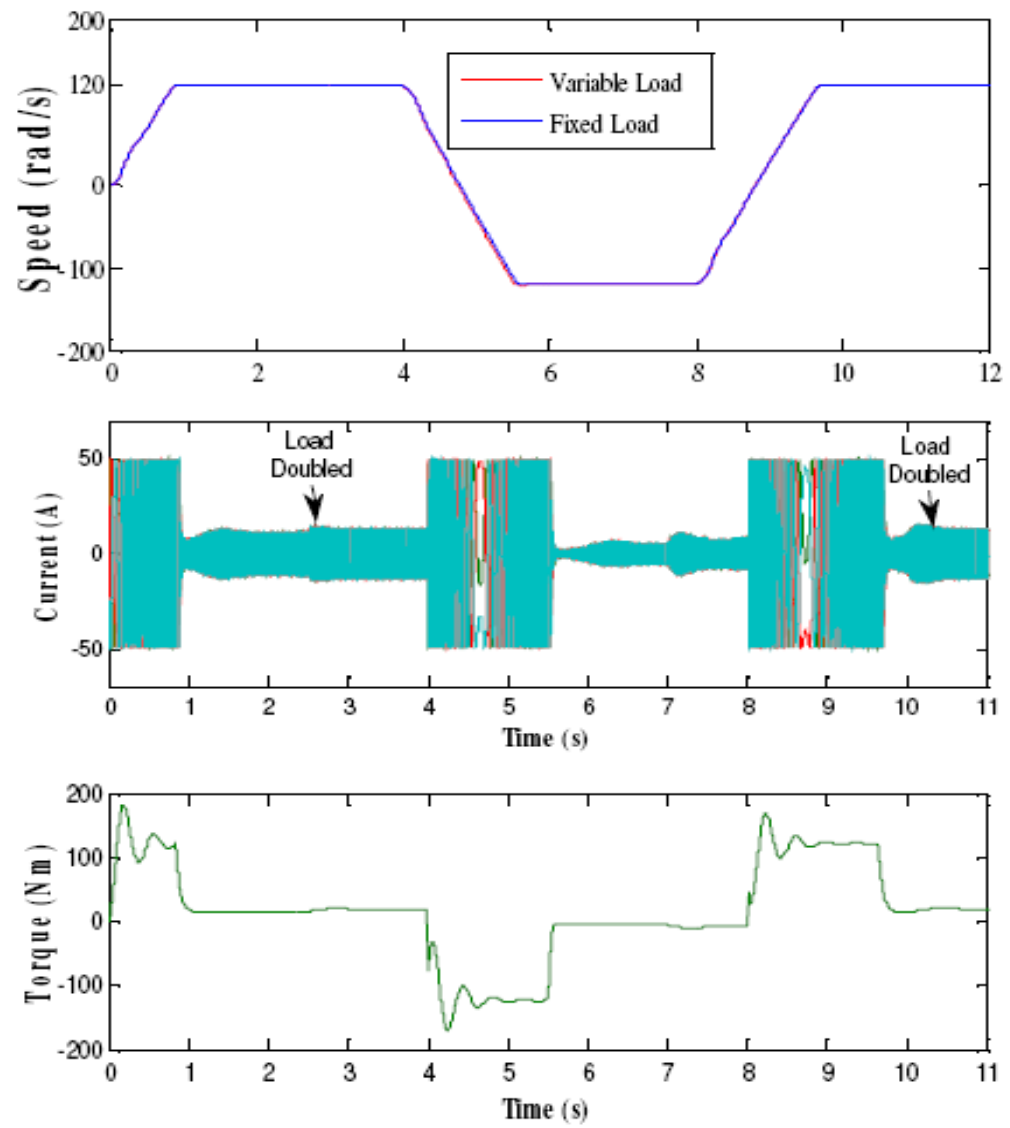

Figure 10 Effect of rotor resistance change for F/NF controller (see online version for colours)

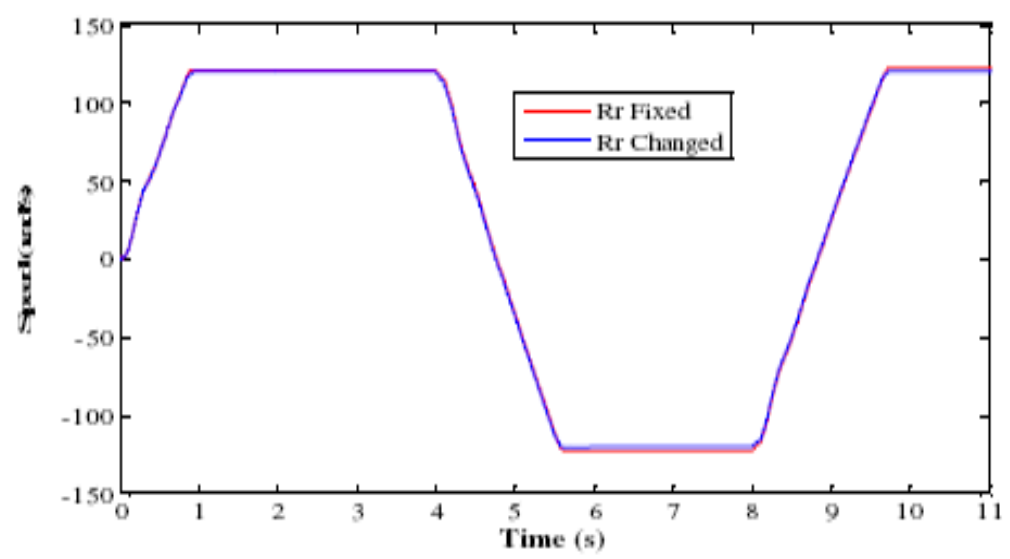


Figure 10 Effect of rotor resistance change for F/NF controller (continued) (see online version for colours)
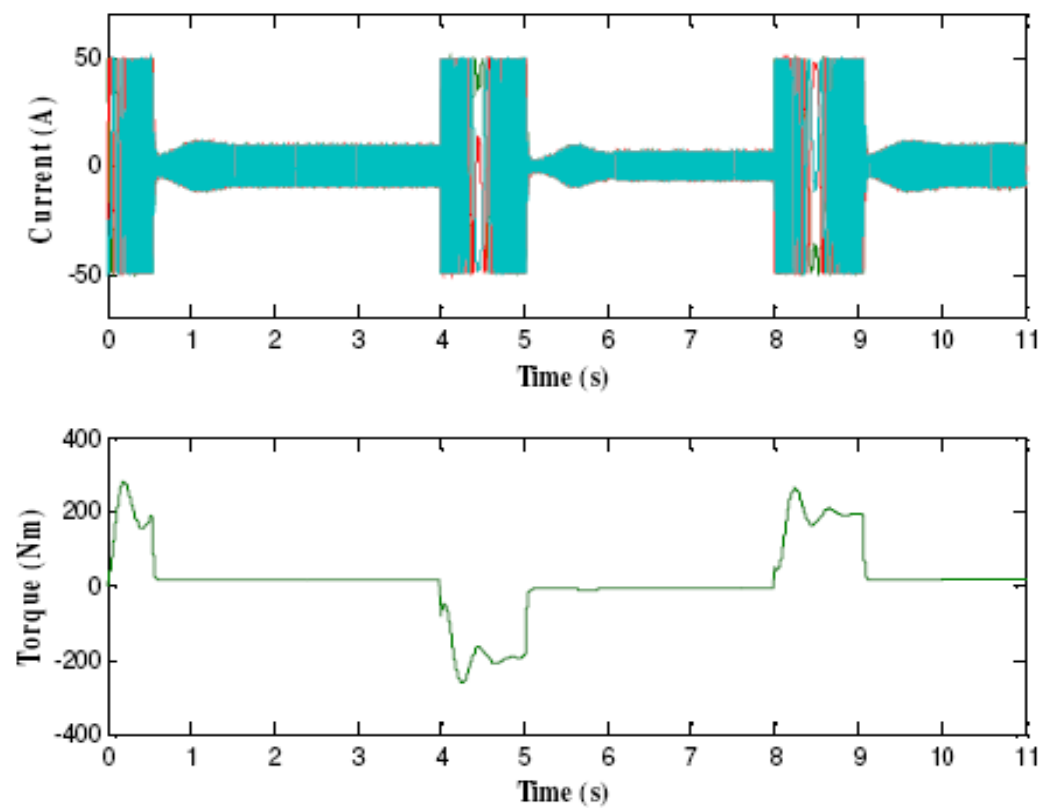

In Figure 10, the effect of load torque change for NF/NF controller is shown. At $\mathrm{t}=2.5 \mathrm{~s}$ the load torque is increased from $100 \%$ to $200 \%$, again decreased to $100 \%$ at time $\mathrm{t}=7 \mathrm{sec}$. At time $\mathrm{t}=10 \mathrm{sec}$. load is again increased to $200 \%$, the speed has been dropped from $120.1 \mathrm{rad} / \mathrm{s}$ to $119.8 \mathrm{rad} / \mathrm{sec}$ and is recovered to $120.08 \mathrm{rad} / \mathrm{s}$ in $0.3 \mathrm{~seconds}$. Figure 11 shows the effect of rotor resistance change for NF/NF controller, the speed error is small and is $0.31 \mathrm{rad} / \mathrm{s}$ as compared to the $\mathrm{F} / \mathrm{NF}$ controller.

Figure 11 Effect of rotor resistance for NF/NF controller (see online version for colours)

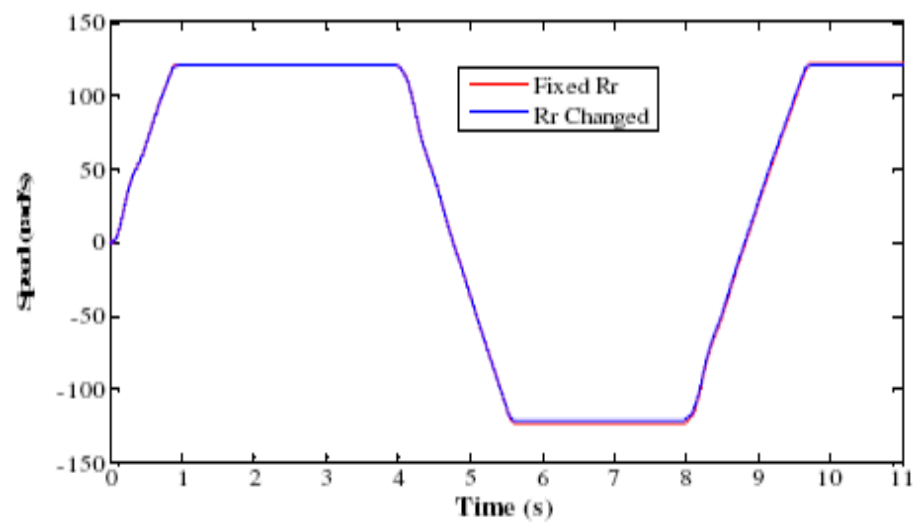


Figure 11 Effect of rotor resistance for NF/NF controller (continued) (see online version for colours)
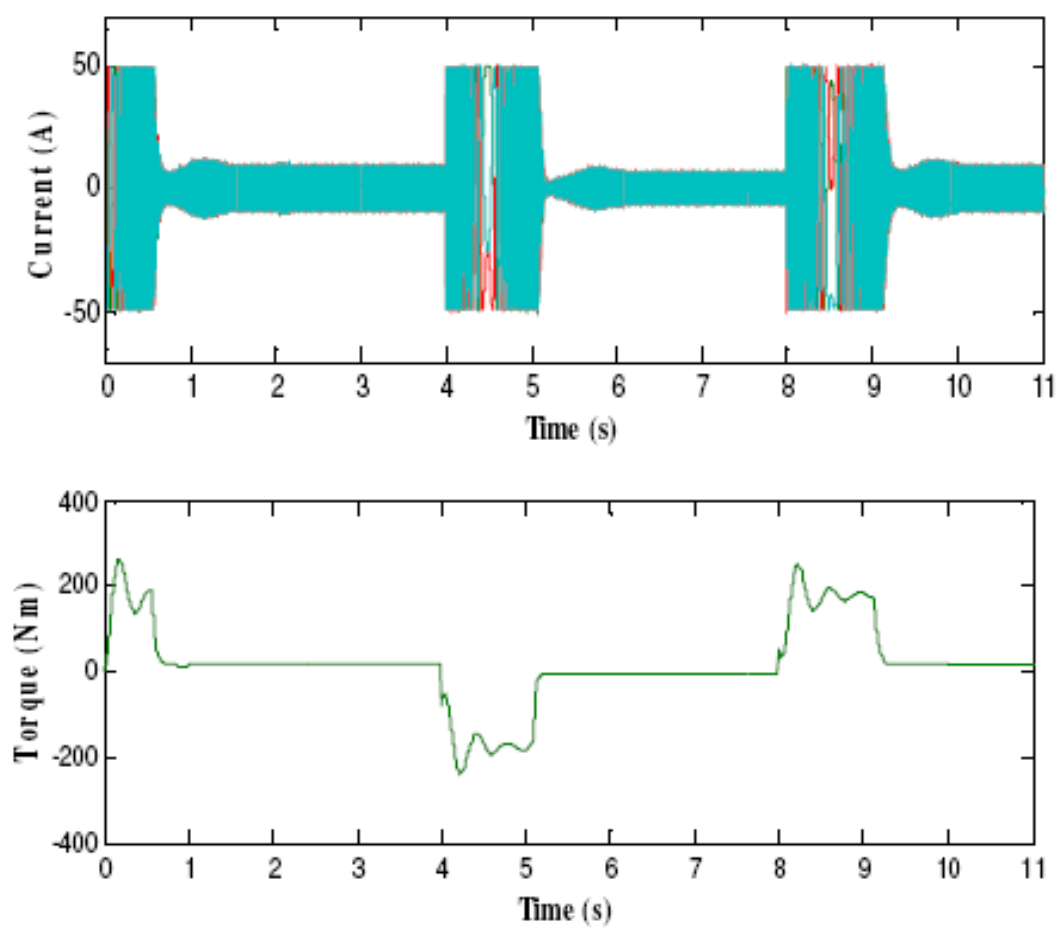

\section{Conclusions}

In the proposed two-stage control technique, with an independent control of slip frequency and current magnitude for an induction machine drive, F/NF and NF/NF controllers are implemented to control the frequency and current respectively. The performance of $\mathrm{NF} / \mathrm{NF}$ controller in two stages is better as compared to $\mathrm{F} / \mathrm{NF}$ controller for the same. The faster settling time, low steady state error and better dynamic performance is achieved and is tested for parameter variations such as load torque and increased rotor resistance up to double of the value. With NF/NF control in two stages, drive gives satisfactory results without much deviation from the set values. Hence, $\mathrm{NF} / \mathrm{NF}$ controller for two stages in induction machine drive is recommended for the applications where variable load and high starting torque is required such as tractions and elevators, etc. 


\section{References}

Ba-razzouk, A., Cheriti, A. and Oliver, G. (1997) 'A neural networks based field oriented control scheme for induction motors', Industry Applications Conference, New Orleans, Vol. 2. pp.804-811.

Chen, C-S. (2011) 'Adaptive network based fuzzy inference system. Robust self-organizing neural-fuzzy control with uncertainty observer for MIMO nonlinear systems', IEEE Transactions on Fuzzy Systems, August, Vol. 19, No. 4, pp.694-706.

Gaur, P., Singh, B. and Mittal, A.P. (2008) 'Steady state and dynamic response of a state space observer based PMSM drive with different controllers', Journal of Power Electronics, July, Vol. 8, No. 3, pp.280-290.

Harnefors, L. (2001) 'Design and analysis of general rotor flux-oriented vector control systems', IEEE Trans. Ind. Electron, Vol. 48, No. 2, pp.383-390.

Shi, K.L., Chan, T.F. and Wong, Y.K. (1997) 'Modelling of the three-phase Induction motor using Simulink', Electrical Machine and Drive Conf, pp.WB3/6.1-WB3/6.3.

Shi, K.L., Chan, T.F., Wong, Y.K. and Ho, S.L. (2001) 'A novel hybrid fuzzy/PI two-stage controller for an induction motor drive', IEMDC 2001, 17-20 June, pp.415-421.

Wlas, M., Krzeminśki, Z., Guzinśki, J., Abu-Rub, H. and Toliyat, H.A. (2005)

'Artificial-neural-network-based sensorless nonlinear control of induction motors', IEEE

Transactions on Energy Conversion, September, Vol. 20, No. 3, pp.520-528.

\section{Appendix}

\section{Motor parameters}

\begin{tabular}{lc}
\hline Rated power & $10 \mathrm{HP}$ \\
Rated stator voltage & $220 \mathrm{~V}$ \\
Rated frequency & $60 \mathrm{HZ}$ \\
Rated speed & $1,160 \mathrm{RPM}$ \\
No. of poles & 6 \\
Stator resistance & $0.282 \Omega / \mathrm{ph}$ \\
Stator leakage reactance & $0.512 \Omega / \mathrm{ph}$ \\
Rotor resistance referred to stator & $0.152 \Omega / \mathrm{ph}$ \\
Rotor leakage reactance & $0.152 \Omega / \mathrm{ph}$ \\
Referred to stator & \\
Magnetic reactance & $4.865 \Omega / \mathrm{ph}$ \\
Coefficient of friction & 0.124 \\
Moment of inertia of & $0.4 \mathrm{~kg} \mathrm{~m} \mathrm{~m}^{2}$ \\
\hline
\end{tabular}

